\title{
Differences in licensee, police and public opinions regarding interventions to reduce alcohol-related harm associated with licensed premises
}

\begin{abstract}
Objectives: To determine the level of support by licensees, police and the general public for interventions to reduce alcohol-related harm associated with licensed premises and to identify differences between the three groups. Methods: Participants were 108 licensees of premises licensed to sell alcohol; 132 police officers; 200 members of the public. Questionnaires were administered either through work settings or by mail. Respondents' levels of agreement with interventions to reduce alcohol-related harm associated with licensed premises: responsible service of alcohol; security and crowd control; policing; patron transport; and linking of alcohol-related harm to licensed premises and communication. Results: Police and members of the public were significantly more likely than licensees to agree with strategies under licensee control, such as subsidising patron transport and training staff to deal with intoxicated patrons. Police were more likely than licensees and members of the public to agree with strategies requiring community action and changes to liquor licensing laws. Licensees had significantly lower levels of agreement than the other groups about licensees' responsibility to reduce alcohol-related harm as a consequence of drinking at their premises. Conclusions: While there was good agreement between police officers and members of the public about strategies for reducing alcohol-related harm at licensed premises, licensees held divergent views about strategies within their control. Licensees were less likely than police and members of the public to agree they were responsible for reducing alcohol-related harm resulting from drinking at their premises.
\end{abstract}

Key words: licensed premises, alcohol, alcohol-related harm, police, responsible service of alcohol.

Aust N Z J Public Health. 2009; 33:160-6 doi: 10.1111/j.1753-6405.2009.00364.x

\author{
Nathan Hawkins, Rob Sanson-Fisher, Anthony Shakeshaft \\ and Gloria Webb \\ School of Medicine and Public Health, University of Newcastle, New South Wales
}

A lcohol costs Australian society more than $\$ 15$ billion in harms annually. ${ }^{1}$ Alcohol related violence, for example, results in at least 62,534 serious alcohol-related assaults and 8,661 hospital admissions annually. ${ }^{2}$ Further, licensed premises are linked to high levels of alcohol-related harm, ${ }^{3-8}$ including assaults, drink-driving, road traffic crashes, ${ }^{3}$ property crimes $^{4}$ and domestic violence. ${ }^{5}$

Methods for reducing alcohol-related harm fall into four groups: education; policy interventions; economic interventions; and organisational interventions. Education interventions target schools, colleges and universities and the general public. Policy interventions include drink-driving legislation, sobriety checkpoints, increased penalties for drink-driving, restrictions on advertising and promotion of alcohol, and mandatory health and safety warnings. Economic interventions include the pricing of alcohol through taxation. ${ }^{6}$ Organisational interventions include responsible server programs, ${ }^{7-9}$ training for nightclub bouncers in handling drunken and potentially violent clients, community action projects, alcohol accords and alcohol linking programs. ${ }^{10}$

Responsible server programs are particularly common. Early studies showed positive results such as increases in staff interventions to slow or stop consumption of alcohol by pseudo-drunk customers, ${ }^{7}$ changes in server behaviour, ${ }^{7}$ changes in bar staffs' knowledge about responsible service issues, decreases in the numbers of patrons leaving premises with blood alcohol concentrations (BAC) above $0.08,{ }^{9}$ higher levels of desired server behaviour ${ }^{11}$ and lower BACs of patrons served by trained staff compared with untrained staff. ${ }^{7}$

Studies have also evaluated enforcement of liquor licensing laws and feedback by police to licensed premises about contraventions of the laws. Studies show substantial increases in refusals of service to intoxicated customers and reductions in drink-driving, ${ }^{12}$ and reductions in the proportions of liquor stores willing to sell alcohol to under-age drinkers. ${ }^{13}$ This suggests enforcement is more effective than responsible server programs on their own. ${ }^{14}$

A series of large-scale studies trialed the effectiveness of combining law enforcement with responsible server programs, with mixed results. An early study showed a $20 \%$ reduction in public order offences after the introduction of the program, the effect was not sustained. ${ }^{15}$ Attempts to replicate this study have shown disappointing results. ${ }^{14,16}$

A method utilising both law enforcement and responsible service is the alcohol accord, where key groups are mobilised to work in a co-operative manner. Again, these studies have shown mixed results. The Surfer's Safety Action project, undertaken in a tourism area in Queensland, resulted in significant improvements in policies and practices in licensed premises and a halving of observed violent incidents. ${ }^{17}$ The Geelong Accord in Victoria reported a halving of assault offences. ${ }^{18}$ However, 
no control group was employed, thus weakening the findings. ${ }^{14}$ The Fremantle project in Western Australia found an increase in assault offences in public places. ${ }^{19}$ However, this may have been a response to a greater police presence and an increased likelihood of police detection and the fact that police may have been involved in some of the assaults. ${ }^{14}$

Enforcement can also relate to drink-driving laws, rather than liquor licensing laws. A large-scale study in Oregon in the US, trialing community action interventions, responsible service, limiting access to alcohol and increased enforcement of drinkdriving laws, found that night-time road traffic crashes resulting in injury declined by $10 \%$, crashes where the driver had been drinking declined by $6 \%$, and assault injuries presenting to hospital emergency departments declined by $43 \%{ }^{20}$

This study was concerned with ascertaining the acceptability of various types of interventions to reduce alcohol-related harm associated with licensed premises. It explored the attitudes, beliefs and knowledge of three key groups - licensees, police officers and members of the general public - whose support is crucial to the effectiveness of possible interventions for reducing alcohol-related harm in and near licensed premises.

\section{Aims}

To determine the level of support by licensees, police and the general public for interventions to reduce alcohol-related harm associated with licensed premises and to identify differences between the three groups in beliefs about primary responsibility for reducing such harm.

\section{Methods \\ Participants}

Participants were recruited in rural New South Wales from three groups: licensees of premises licensed to sell alcohol, police officers and members of the public.

\section{Licensees}

The licensee sample was recruited by obtaining a random sample of 400 licensed premises including restaurants, clubs, pubs, hotels, taverns, bottle shops, function centers, liquor stores, wineries and vineyards. The premises were identified from the electronic Yellow Pages, a free and exhaustive listing of businesses and service providers.

Each licensed premises was sent a survey pack containing a covering letter with a brief introduction to the study, an information sheet, a questionnaire and a reply-paid return envelope. If no response was received after three weeks a reminder survey pack was mailed.

At a $95 \%$ confidence interval and an error tolerance of $5 \%$ a total of 130 responses was required for the purposes of statistical analysis. With return rates conservatively estimated at $30 \%$, it was calculated that a sample size of 400 would yield sufficient power.

\section{Police}

The recruitment method for police was developed through consultation with senior police officers of the New South Wales Police Force. Each Local Area Commander in rural areas of New South Wales was sent a survey pack containing a covering letter explaining the purpose of the research and five copies of the survey (including reply-paid return envelopes) for distribution to officers in the area.

Three weeks after the initial mail-out a reminder letter and five survey packs were sent to all Local Area Commands from which fewer than five responses had been received. A week later, reminder phone calls were made to each Local Area Commander from whose area fewer than five surveys had been received.

A total of 28 Local Area Commands were selected, with 140 police officers invited to participate.

\section{General public}

General public participants were recruited using Australian Electoral Commission (AEC) records. Voting is compulsory in Australia for all citizens aged 18 years and older, and the AEC holds records for all persons who are registered to vote. The AEC provided a random sample of 600 potential participants from rural areas, stratified by electoral division, age range (between 18 and 62 years) and gender.

Potential participants were mailed a survey pack containing a covering letter, an information sheet and the survey instrument. If no response was received after three weeks a reminder survey pack was mailed.

A minimum of 200 survey responses was required to achieve maximum error tolerance of $\pm 7 \%$ (95\% confidence interval). To allow for a response rate as low as $30 \%$, survey packs were mailed to 600 potential participants.

\section{Survey Instrument}

The self-completed, paper-based brief questionnaire had a maximum Flesch Kincaid reading age of eight years, as recommended by the Ethics Committee.

\section{Common items}

The questionnaire contained 32 items common to all participants. Twenty-nine suggested interventions for reducing alcohol-related harms associated with licensed premises consumption and were presented randomly (Table 1). Interventions were selected according to the six broad categories identified in the New South Wales Department of Gaming and Racing recommendations for establishing Liquor Accords: responsible service; security and crowd control; policing; patron transport; linking; and communication. The interventions included both voluntary and currently legislated strategies. Participants were asked to rate on a five-point Likert scale the strength of their agreement with each proposed intervention, with the responses ranging from "Strongly agree" to "Strongly disagree". 


\section{Responsibility for reducing alcohol-related harm}

Three items asked participants to rate who they felt should do more to help reduce alcohol-related harms: licensees, police or the general public.

Items specific to each participant group.

\section{Licensees}

Four items specifically for licensees concerned the respondent's age and gender, type of licensed premises and average number of weekly patrons at the premises.

\section{Police}

Five items specifically for police concerned the respondent's age, gender, official rank, official duties related to alcohol sales and the number of official police visits made to licensed premises in the previous six months.

\section{General public}

Three items specifically for the general public concerned the respondent's age, gender and number of visits made to licensed premises in the previous six months.

\section{Statistical analysis}

\section{Data preparation}

Participants who provided logically inconsistent responses were removed from the dataset.
To conduct $\mathrm{Chi}^{2}$ analyses respondents were collapsed into one of two categories for each item, according to their response: Agree (including "Slightly agree" and "Strongly agree") and "Other".

\section{Response rate}

Response rates were calculated independently for each participant group as a percentage of all invitees in that group.

\section{Rate of agreement}

Rates of agreement were calculated as the percentage and were compared according to participant group using Fishers Exact $\mathrm{Chi}^{2}$ analysis.

\section{Results \\ Response rates}

\section{Licensees}

Of the 400 licensee invited to participate, five surveys (1\%) were returned as incorrectly addressed and 108 were completed and returned. This resulted in a $27.3 \%$ return rate.

\section{Police}

Of the 140 Police invited to participate across 28 Local Area Commands, 132 completed surveys were returned from 27 Local Area Commands, a $94.3 \%$ return rate.

\section{Table 1: Twenty-nine suggested interventions for reducing alcohol-related harms used in the questionnaire.}

\section{Responsible service}

- Increase fines and penalties for licensees who do not serve alcohol responsibly

- Reduce licensed premises and retail liquor outlet trading hours

- Do not serve patrons who are intoxicated

- Refuse entry to licensed premises for persons who are intoxicated

- Ask patrons who are intoxicated to leave licensed premises

- Check proof of age for all younger persons who may appear under 18 on entry to licensed premises

- Limit discounted alcohol sales to traditional 'happy hours' of no more than 120 minutes per day

- Restrict large volume takeaway sales (e.g. between midday and $8.00 \mathrm{pm})$

- Provide take-away customers with information (e.g. flyers) about 'responsible service' and 'hosting a party'

- Provide free bar food in pubs and clubs to slow the effects of alcohol

- Display visible safe drinking materials (e.g. posters, coasters and staff T-shirts) in licensed premises

\section{Patron transport}

- Provide designated drivers with free non-alcoholic drinks

- Provide free breathalysers in pubs and clubs so that patrons can test their blood alcohol content

- Provide subsidised transport from pubs and clubs to home (e.g. flat-rate taxi/free minibus)

- Increase penalties for drink-driving

- Provide free telephones from licensed premises to local taxi service

\section{Policing}

- Increase visible police random breath testing at times likely to catch drink drivers (e.g. the early hours of the morning)

- Increase visible police checks of responsible service practices on licensed premises

\section{Security and crowd control}

- Increase training of bar and security staff for handling of intoxicated and potentially violent patrons

- Stagger closing times of licensed premises in close proximity to each other to reduce possible crowd sizes and increase patron safety

- Increase 'alcohol-free zones' in the community

- Limit the number of licensed premises and retail liquor outlets in a community

- Reduce the total number of people that are currently allowed in a pub or club at one time

- Introduce 'lockout' times (i.e. time after which no new patrons can enter a licensed premises, but existing patrons can stay)

\section{Linking}

Get police to investigate where intoxicated offenders consumed alcohol and, if necessary, warn offending licensed premises that their patrons are getting drunk on their premises

- Hold licensees legally responsible for the behavior of intoxicated patrons after they have left the licensed premises

- Increase responsible service of alcohol checks and prosecution by liquor licensing authorities

\section{Communication}

local communities

- Promote responsible drinking through the local media 


\section{General public}

Of the 600 members of the general public invited to participate, $27(4.5 \%)$ were returned as incorrectly addressed and three (0.5\%) requested removal from the mail-out database. Two hundred completed surveys were returned, a return rate of $34.9 \%$.

\section{Respondent profile}

\section{Licensees}

The 108 licensee responders included $4 \%$ aged less than 27 years, $23 \%$ aged $28-37$ years, $43 \%$ aged $38-52$ years and $32 \%$ aged 53 years or older. Overall, $69 \%$ were male. The type of licensed premises represented varied and included $64 \%$ from a pub or club, 20\% from a take-away or bottle shop premises, $9 \%$ from a restaurant or function centre and $8 \%$ from a winery. The reported average weekly patronage of premises was 758 patrons.

\section{Police}

The 132 police responders included $8 \%$ aged less than 27 years, $46 \%$ aged $28-37$ years, $44 \%$ aged $38-52$ years and $3 \%$ aged 53 years or older. Overall, $80 \%$ were male. Respondents were $14 \%$ Constables, $50 \%$ Senior Constables, 25\% Sergeants and 11\%
Inspectors. Forty-one police reported licensing activities as part of their specific role and the average respondent made 54 official visits to licensed premises in the past six months.

\section{General Public}

The 200 responders from the general public included $7 \%$ aged less than 27 years, $17 \%$ aged $28-37$ years, $39 \%$ aged $38-52$ years and $35 \%$ aged 53 years or older. Overall, $45 \%$ were male. Responders visited a licensed premises and average of 36 times in the past six months.

\section{Rates of agreement}

High rates of agreement ( $60 \%$ or greater) occurred across the three respondent groups for 10 of the 32 strategies (Table 3 ). The four strategies with the highest levels of agreement across all groups related to preventing under-age drinking (98.4\% agreement for all groups combined), and strategies for dealing with intoxicated persons $(94.4 \%$ to $97.3 \%$ agreement for all groups combined). The other strategies related to promotion of responsible drinking $(61.1 \%$ to $89.0 \%$ agreement for all groups combined), drink-driving $(78.2 \%$ to $83.2 \%$ agreement for all

Table 2: Rates of agreement of more than $60 \%$ for licensees, police and the general public.

\begin{tabular}{|c|c|c|c|c|c|}
\hline & Licensees & Police & $\begin{array}{l}\text { General } \\
\text { Public }\end{array}$ & Combined & $\chi^{2}$ \\
\hline $\begin{array}{l}\text { Check proof of age for all younger persons who may } \\
\text { appear under } 18 \text { on entry to licensed premises }\end{array}$ & 100.0 & 97.0 & 98.5 & 98.4 & $p=0.175$ \\
\hline $\begin{array}{l}\text { Refuse entry to licensed premises for persons who are } \\
\text { intoxicated }\end{array}$ & 99.1 & 97.0 & 96.5 & 97.3 & $p=0.370$ \\
\hline Do not serve patrons who are intoxicated & 96.5 & 97.0 & 95.5 & 96.2 & $p=0.754$ \\
\hline $\begin{array}{l}\text { Ask patrons who are intoxicated to leave licensed } \\
\text { premises }\end{array}$ & 96.4 & 96.3 & 91.9 & 94.4 & $p=0.130$ \\
\hline Promote responsible drinking through the local media & 85.8 & 88.9 & 91.0 & 89.0 & $p=0.380$ \\
\hline $\begin{array}{l}\text { Increase visible police random breath-testing at times } \\
\text { likely to catch drink drivers (e.g. during the early hours } \\
\text { of the morning) }\end{array}$ & 74.3 & 86.7 & 85.9 & 83.2 & $p=0.014$ \\
\hline Increase penalties for drink-driving & 72.3 & 81.5 & 79.3 & 78.2 & $p=0.196$ \\
\hline $\begin{array}{l}\text { Display visible safe-drinking materials (e.g. posters, } \\
\text { coasters and staff T-shirts) in licensed premises }\end{array}$ & 72.8 & 73.3 & 82.9 & 77.4 & $p=0.044$ \\
\hline $\begin{array}{l}\text { Limit discounted alcohol sales to traditional 'happy hours' } \\
\text { of no more than } 120 \text { minutes per day }\end{array}$ & 76.6 & 77.8 & 71.7 & 74.8 & $p=0.403$ \\
\hline $\begin{array}{l}\text { Provide take-away customers with information (e.g. flyers) } \\
\text { about 'responsible service' and 'hosting a party' }\end{array}$ & 61.1 & 65.9 & 62.1 & 63.0 & $p=0.690$ \\
\hline
\end{tabular}

Table 3: Rate of agreement significantly higher among police and the general public than among licensees.

\begin{tabular}{|c|c|c|c|c|c|}
\hline & Licensees & Police & General Public & Combined & $\chi^{2}$ \\
\hline Provide designated drivers with free non-alcoholic drinks & 76.1 & 90.3 & 91.3 & 87.1 & $p=0.000$ \\
\hline $\begin{array}{l}\text { Increase training of bar and security staff for handling of } \\
\text { intoxicated and potentially violent patrons }\end{array}$ & 70.3 & 91.9 & 90.9 & 86.0 & $p=0.000$ \\
\hline $\begin{array}{l}\text { Provide free telephones from licensed premises to local } \\
\text { taxi service }\end{array}$ & 76.1 & 85.9 & 91.4 & 85.9 & $p=0.001$ \\
\hline $\begin{array}{l}\text { Increase visible police checks of responsible service } \\
\text { practices on licensed premises }\end{array}$ & 62.2 & 88.1 & 82.3 & 79.0 & $p=0.000$ \\
\hline $\begin{array}{l}\text { Provide subsidised transport from pubs and clubs to home } \\
\text { (e.g. flat-rate taxi or free minibus) }\end{array}$ & 64.9 & 83.0 & 82.4 & 78.2 & $p=0.000$ \\
\hline $\begin{array}{l}\text { Get police to investigate where intoxicated offenders } \\
\text { consumed alcohol and, if necessary, warn offending licensed } \\
\text { premises that their patrons are getting drunk on their premises }\end{array}$ & 50.9 & 81.5 & 75.6 & 71.2 & $p=0.000$ \\
\hline $\begin{array}{l}\text { Provide free bar food in pubs and clubs to slow the effects } \\
\text { of alcohol }\end{array}$ & 45.1 & 77.0 & 68.8 & 65.3 & $p=0.000$ \\
\hline
\end{tabular}


groups combined) and limitations to discounted drinks promotions (74.8\% agreement across all groups combined).

A further seven strategies had rates of agreement that were significantly higher among police and the general public, than licensees (Table 4). The majority of these strategies relate to the operation of licensed premises: provision of free non-alcoholic drinks to designated drivers; increased training for bar staff; free telephones to local taxi services; subsidised transport home from the licensed premises; and free bar food to slow the effects of alcohol. The other two strategies related to police activities: increased checks of responsible service practices; and investigations by police of licensed premises used by intoxicated offenders with feedback to, but not punishment of, the relevant licensed premises.

Eight strategies had rates of agreement that were highest among police compared with the general public and licensees (Table 5). They include alcohol accords, lockout times, increased checks by liquor licensing authority of responsible server provisions, alcohol-free zones, staggered closing times, and reduction of hours of operation and numbers of liquor outlets.

Rates of agreement were significantly higher among licensees than police and the general public for one strategy: the provision of breathalysers in pubs and clubs so that patrons can test their blood alcohol levels. Ninety-three per cent of the general public agreed, compared to $73.5 \%$ of licensees and only $54.1 \%$ of Police.

Three strategies had low (less than 50\%) mean rates of agreement among the respondent groups. The greatest disparity was in the strategy of holding licensees responsible for behaviour of intoxicated patrons after leaving licensed premises, with $8.8 \%$, $68.7 \%$ and $33.0 \%$ agreement respectively for licensees, police and the general public. A large disparity also occurred for reducing the total number of people that are allowed in a pub or club at one time, with $15 \%, 68.1 \%$ and $42.2 \%$ agreeing as above. Similarly, restricting large-volume take-away sales was only agreed with by $20.5 \%, 63.4 \%$ and $41.4 \%$ of licensees, police and the general public, respectively.
For the item about who should take responsibility for reducing alcohol-related harm associated with licensed premises, there were significant differences in levels of agreement among the three groups for all three items. Those that agreed police should do more included $54.5 \%$ or licensees, $51.9 \%$ of police and $66.7 \%$ of the general public. Those that felt the general public should do more included $88.4 \%$ of licensees, $95.6 \%$ of Police and $86.8 \%$ of the general public. Those that agreed licensees should do more included $46.4 \%$ of licensees, $95.6 \%$ of police and $82.7 \%$ of the general public.

\section{Discussion}

An important limitation of the study is the low response rates for return of questionnaires by licensees and members of the public (27.3\% and $34.9 \%$ respectively). Licensees may have interpreted the survey's focus on alcohol-related harm as negative. Australian Electoral Commission records may also have inaccuracies that meant survey packs couldn't be delivered. Further, persons who do not drink or who have not experienced alcohol-related harm, may not have felt the topic was important, while heavy drinkers or those who have participated in alcohol-related harm (e.g. drink-driving or assault), may have felt the topic was threatening.

Another limitation is that this study only examined rates of agreement, which are an indicator only of potentially successful interventions. When it comes to implementing one or more of these interventions levels of support may in practice be low. Future research may usefully get respondents to compare and prioritise these interventions against each other and other public policies.

The study found very high levels of agreement among licensees, police and members of the public for interventions concerned with preventing under-age drinking, dealing with intoxicated persons, promotion of responsible drinking, preventing drink-driving and limiting discounted sales of alcohol.

Some strategies had significantly higher rates of agreement among police and members of the public, compared with licensees. Most of these related to areas where licensees have greatest control,

Table 4: Rate of agreement significantly higher among police than the general public or licensees.

\begin{tabular}{|c|c|c|c|c|c|}
\hline & Licensees & Police & General Public & Combined & $\chi^{2}$ \\
\hline $\begin{array}{l}\text { Establish liquor accord agreements between licensees, police } \\
\text { and local communities }\end{array}$ & 77.9 & 90.4 & 75.9 & 80.8 & $p=0.003$ \\
\hline $\begin{array}{l}\text { Introduce 'lockout' times (i.e. time after which no new patrons } \\
\text { can enter a licensed premises, but existing patrons can stay) }\end{array}$ & 70.5 & 95.6 & 71.4 & 78.5 & $p=0.000$ \\
\hline $\begin{array}{l}\text { Increase responsible service of alcohol checks and } \\
\text { prosecution by liquor licensing authorities }\end{array}$ & 54.9 & 92.6 & 79.7 & 77.3 & $p=0.000$ \\
\hline Increase 'alcohol-free zones' in the community & 63.4 & 87.4 & 76.8 & 76.6 & $p=0.000$ \\
\hline $\begin{array}{l}\text { Increase fines and penalties for licensees who do not serve } \\
\text { alcohol responsibly }\end{array}$ & 53.6 & 91.9 & 73.7 & 74.2 & $p=0.000$ \\
\hline $\begin{array}{l}\text { Stagger closing times of licensed premises in close proximity } \\
\text { to each other to reduce possible crowd sizes and increase } \\
\text { patron safety }\end{array}$ & 51.8 & 74.6 & 55.8 & 60.5 & $p=0.000$ \\
\hline $\begin{array}{l}\text { Reduce licensed premises and retail liquor outlet trading } \\
\text { hours }\end{array}$ & 25.9 & 77.8 & 48.5 & 51.7 & $p=0.000$ \\
\hline $\begin{array}{l}\text { Limit the number of licensed premises and retail liquor } \\
\text { outlets in a community }\end{array}$ & 51.3 & 67.4 & 39.7 & 51.0 & $p=0.000$ \\
\hline
\end{tabular}


for example, increased training for staff in dealing with intoxicated patrons. Other strategies related to enforcement options, such as increasing police checks on responsible server practices.

A further group of strategies had significantly higher levels of agreement among police compared with the other two groups. Interestingly, these fell outside the area of enforcement, such as reducing numbers of liquor outlets. All of these strategies would require community-wide action and some changes to liquor licensing laws.

Only one strategy had significantly higher rates of agreement by licensees. This item related to provision of breathalysers in pubs and clubs so that patrons could check their blood alcohol concentrations. The effect of such a strategy would be to transfer responsibility for ensuring clients did not get intoxicated to patrons, rather than licensees, management and bar staff. Installing breathalysers in licensed premises has had mixed results. Some studies show a reduction in drink driving behaviours ${ }^{21}$ however other studies have shown inaccuracies in the recording devices and competition among drinkers to see who can become the most intoxicated. ${ }^{22,23}$

For the items regarding responsibility for reducing alcoholrelated harm, the licensees had low levels of agreement that this was their responsibility. This put them at odds with the other two groups, and may provide some explanation for the reported lack of action taken by licensees to reduce alcohol-related harm in and around their licensed premises.

Overall, it appears that police officers have fairly concordant beliefs with members of the public, but licensees do not agree with strategies that would require them to take action to prevent alcohol-related harm. This suggests that there remains a need for change in licensees' attitudes and behaviour.

An important consideration is that there are clear commercial imperatives governing licensees' behaviour. ${ }^{14}$ If licensees take action to reduce alcohol consumption, they may be putting profits in jeopardy. Licensees in this study had low levels of agreement with strategies that would cost them money. If licensees who are attempting to behave responsibly see other licensees flaunting laws about service of alcohol to intoxicated patrons and encouragement of binge drinking through discounting alcoholic drinks, for example, they may feel less likely to continue behaving responsibly. Stockwell $(2001)^{14}$ points to the need for disincentives for licensees to act irresponsibly. Such disincentives would go some way towards offsetting the commercial imperatives discussed above.

The motivations and attitudes of licensees include the desire to be profitable and to stay out of trouble with liquor licensing agents. Homel and Clark (1995) note the lack of legislative or economic reasons in Australia for licensees to introduce and maintain responsible server practices. They believe that the attitudes and practices of all licensees, not just licensees of high-risk venues, need to be changed, with the result of change over time in attitudes and behaviour in the whole industry. ${ }^{24}$

With regard to enforcement, a study of enforcement behaviour of police in Australia found that police direct most of their enforcement efforts to individual drinkers, rather than licensing venues or venue staff. ${ }^{25}$ Barriers against more effective enforcement action by police include lack of skill, low priority given to alcohol policing, the limited time available and the inadequate penalties given by the courts. ${ }^{26,27}$

Research with police officers has shown strong support for the principles of responsible service, with $93 \%$ of police stating that alcohol servers should be responsible for preventing intoxication. Moreover, $86 \%$ believed that ensuring licensee compliance with liquor licensing laws is an appropriate aspect of police work. ${ }^{26}$

The findings of this study are in agreement with those of a study into public support for different policies aimed at reducing alcohol consumption. ${ }^{28}$ Public attitudes to regulation of alcohol provide strong support for measures related to availability, control and promotion of alcohol. ${ }^{28}$ These study results indicate that police, members of the public and licensees would support the introduction of a range of measures to reduce alcohol-related harm associated with licensed premises. However, licensees do not show strong support for methods that fall within their areas of responsibility.

The political and social climate is important in bringing about change in practices at licensed premises. ${ }^{14}$ Homel and Clark (1995) ${ }^{24}$ advocate putting pressure on licensees to act responsibly by using the community as a lever to bring about change. Clearly, the community would need to be supportive of changes for this method to work. Strategies to bring about change in attitudes and behaviour include advocacy groups, publicity, and release of data about local levels of alcohol-related harm to the general public and to local decision-makers in the liquor industry. ${ }^{14}$

Wiggers et al. (2004) ${ }^{10}$ concluded that the risk of alcohol-related harm could be reduced by increased compliance by licensees with alcohol pricing and promotion controls, the use of responsible hospitality practices, stricter controls over patron behaviour and changes to the environment and management practices at the licensed venue. Stockwell $(2001)^{14}$ concludes that little is known about the effectiveness of enforcement in achieving harm reduction, and about police factors in enforcement.

Marsden Jacobs Associates (2005) $)^{4}$ suggest a range of options for dealing with lack of compliance by licensees, concluding that the Best Practice methods are regulatory options, a graded sanctions approach to licensing (not simply loss of licence) and reductions in outlet density. Graded sanctions could include sanctions against managers and staff, as well as licensees, sanctions for major companies involved in liquor sales, and sanctions against venues. Stockwell (2001) ${ }^{14}$ supports a graded system of fines for breaches of liquor licensing laws, as these would have less impact on businesses than losing licenses.

There is clearly a need for sufficiently severe penalties for contraventions of liquor licensing laws, in order to increase compliance by licensees. Increased penalties would likely increase licensees' perceptions of the certainty of punishment for noncompliance. Coupled with better enforcement practices, this is likely to be successful in reducing harm associated with drinking at licensed premises. ${ }^{27}$ 


\section{Conclusion}

The survey of attitudes and beliefs of three key groups licensees, police and members of the public to strategies for reducing alcohol-related harm resulting from drinking at licensed premises revealed important differences among the groups. While there were high levels of agreement between police officers and members of the public, licensees held significantly divergent levels of agreement with strategies that are within their control. Licensees also had significantly lower levels of agreement than police and members of the public about licensee responsibility for reducing alcohol-related harm as a result of patrons drinking at their premises. Reasons are suggested for these divergent views.

\section{References}

1. Collins D, Lapsley H. The Cost of Tobacco, Alcohol and Illicit Drug Abuse to Australian Society in 2004/05. Canberra (AUST): Department of Health and Ageing; 2008.

2. Matthews S, Chikritzhs T, Catalano P, Stockwell T, Donath S. Trends in AlcoholRelated Violence in Australia, 1991/92-1999/00. Perth (AUST): National Drug Research Institute; 2002.

3. Lang E, Stockwell T. Drinking locations of drink drivers: a comparative analysis of accident and non accident cases. Accid Anal Prev. 1991;23(6):573-84.

4. Marsden Jacob Associates. Identifying A Framework for Regulation in Packaged Liquor Retailing [report]. Melbourne (AUST): National Competition Council; 2005.

5. Ireland $\mathrm{C}$, Thommeny $\mathrm{J}$. The crime cocktail: licensed premises, alcohol and street offences. Drug Alcohol Rev. 1993;12:143-50.

6. Howat P, Sleet D, Elder R, Maycock B. Preventing alcohol-related traffic injury: a health promotion approach. Traffic Inj Prev. 2004;5(3):208-19.

7. Russ N, Geller E. Training bar personnel to prevent drunken driving: a field evaluation. Am J Public Health. 1987;77(8):952-4.

8. Saltz R. The roles of bars and restaurants in preventing alcohol impaired driving: an evaluation of server intervention. Evaluations \& Health Professions. 1987;10(1):5-27.

9. Lang E, Stockwell T, Rydon P, Beel A. Can training bar staff in responsible serving practices reduce alcohol-related harm? Drug Alcohol Rev. 1998;17(1):39-50.

10. Wiggers J, Jauncey M, Considine R, Daly J, Kingsland M, Purss K, et al. Strategies and outcomes in translating alcohol harm reduction research into practice: the Alcohol Linking Program. Drug Alcohol Rev. 2004;23(3):35564.

11. Buka S, Birdthistle I. Long-term effects of a community-wide alcohol server training intervention. Journal of Studies on Alcohol. 1999;60(1):27-36.
12. McKnight A, Streff F. The effect of enforcement upon service of alcohol to intoxicated patrons of bars and restaurants. Accid Anal Prev. 1994;26(1):7988.

13. Grube J. Preventing sales of alcohol to minors: results from a community trial. Addiction. 1997;92 Suppl 1:251-60.

14. Stockwell T. Responsible alcohol service: lessons from evaluations of seven training and policing initiatives. Drug Alcohol Rev. 2001;20(3):257-65.

15. Jeffs B, Saunders W. Minimizing alcohol related offences by enforcement of the existing licensing legislation. British Journal of Addiction. 1983;78(1):6777.

16. Putnam S, Rockett I, Campbell M. Methodological issues in community-based alcohol-related injury prevention projects: attribution of program effects. In: Greenfield T, Zimmerman R, editors. Experiences with Community Action Projects: New Research in the Prevention of Alcohol and Other Drug Problems. CSAP Prevention Monograph-14. Rockville (MD): Center for Substance Abuse Prevention; 1993. p. 32-42.

17. Homel R, McIlwain G, Carvolth R. Creating safer drinking environments. In: Healther N, Stockwell T, Peters T, editors. Handbook of Alcohol Dependence and Related Problems. Sussex (UK): John Wiley; 2001. p. 235-54.

18. Felson M, Berends R, Richardson B, Veno A. Reducing pub hopping and related crime. In: Homel R, editor. Policing for Prevention: Reducing Crime, Public Intoxication and Injury. New York (NY): Criminal Justice Press; 1997. p. $115-32$.

19. Hawks D, Rydon P, Stockwell T, White M, Chikritzhs T, Heale P. The Evaluation of the Fremantle Police Licensee Accord: Impact on Serving Practices, Harm and the Wider Community. Perth (AUST): National Drug Research Institute, Curtin University of Technology; 1999.

20. Holder HD, Gruenewald PJ, Ponicki WR, Treno AJ, Grube JW, Saltz RF, et al Effect of community-based interventions on high-risk drinking and alcoholrelated injuries. JAMA. 2000;284(18):2341-7.

21. Haworth N, Bowland L. Estimation of Benefit-Cost Ratios for Coin-Operated Breath-testing. Melbourne (AUST): Monash University Accident Research Centre; 1995.

22. Midford R, Masters L, Pillips M, Daly A, Stockwell T, Gahegan M, et al. Alcohol consumption and injury in Western Australia: a spatial correlation analysis using geographic information systems. Aust N Z J Public Health. 1998;22(1):80-5.

23. Crundall I. A Trial of Coin-Operated Breathalysers in the Northern Territory. Darwin (AUST): Alcohol and Other Drug Services, Teritory Health Services; 1996.

24. Homel R, Clark J. The prediction and prevention of violence in pubs and clubs. Crime Prevention Studies. 1995;3:1-46.

25. Findlay R, Sheehan M, Davey J, Brodie H, Rynne F. Liquor law enforcement: policy and practice in Australia. Drugs: Education, Prevention \& Policy. 2002;9(1):85-94.

26. Smith K, Wiggers J, Considine R, Daly J, Collins T. Police knowledge and attitudes regarding crime, the responsible service of alcohol and a proactive alcohol policing strategy. Drug Alcohol Rev. 2001;20(2):181-91.

27. Briscoe S, Donnelly N. Liquor Licensing Enforcement Activity in New South Wales. Canberra (AUST): NSW Bureau of Crime Statistics and Research; 2003.

28. McAllister I. Public attitudes to the regulation of alcohol. Drug Alcohol Rev. $1995 ; 14(2): 179-86$. 